Despite widespread availability of contraception, however, fertility control is not adequate without additional measures to deal with unwanted pregnancies. This has remained true throughout the world and is most certainly true of the United Kingdom. It seems inevitable that abortion on request will be demanded, probably until such time as general sex education is instituted from primary school age onwards and until a sexually mature population can be made socially responsible in the context of family limitation.

It must be remembered that varying attitudes to abortion will lead to different interpretations of the Act and consequently variable abortion rates in different regions. It is our responsibility to see what measures can be taken to ensure that this increased demand can be absorbed into the existing hospital framework, noting in the process additional staff and accommodation required.

While accepting that additional work can lead to delays in outpatient appointments and a lengthening waiting list, we would point out that with the setting up of abortion clinics and operating sessions as outlined there need be no such problem, for we have a negligible waiting list despite this increase in numbers of patients seen.

In the report of a working party of the Royal College of Obstetricians and Gynaecologists (1972) it was suggested by respondents that special units could be set up to deal with abortion cases alone. The outcome of the deliberations on the working of the Abortion Act by the Lane committee are awaited, but it appears that many centres are realizing the need for separate abortion facilities within the hospital environment. The burden of additional admissions will fall on the nursing staff of the gynaecological wards and the operating theatres. It can be argued that a rising therapeutic abortion rate will be followed by a decreasing septic abortion rate, and it may also be expected that there will be a fall in maternity bookings, so freeing nursing staff of one section to help in the other. Obvious hostility has been met in this latter context and is likely to continue until such time as direction is forthcoming regarding interchange of nursing roles between the obstetric and gynaecological services. Despite this we have shown that the working of an abortion unit within a general hospital can be successfully implemented without dislocation of the normal gynaecological service. It can never be entirely successful without the use of day beds, and we hope that this report will stimulate the introduction of such units within the service.

It is with great pleasure that we acknowledge the far-sighted approach of the South East Metropolitan Regional Hospital Board in agreeing to the provision of, and financial responsibility for, these abortion clinics and operating sessions. The nursing staff of the gynaecological wards and operating theatres at Lewisham Hospital and St. John's Hospital deserve the highest praise in cooperating to make the scheme work successfully.

We are indebted to the Upjohn Company for the supply of prostaglandin $\mathrm{F}_{2} \alpha$ used in some of the patients.

\section{References}

British Medical fournal, 1971, 4, 382.

British Medical fournal, 1972, 2, 65.

Buckle, A. E. R., Anderson, Mary M., and Loung, K. C. (1970). British

Medical fournal, 2, 456.
Buckle, A. E. R., and Loung, K. C. (1971). Fournal of Biosocial Science, 3, 289.

Department of Health and Social Security (1971), E/A223/8, 18 October. Lancet, 1971, 2, 1239.

Lewis, Stella C., Lal, Shirley, Branch, B., and Beard, R. W. (1971). British Medical fournal, 4, 606.

Loung, K. C., Buckle, A. E. R., and Anderson, Mary M. (1971). British Medical fournal, 4, 477 .

Royal College of Obstetricians and Gynaecologists (1972). Unplanned Pregnancy. London, R.C.O.G.

Sood, S. V. (1971). British Medical fournal, 4, 270.

Stallworthy, J. A., Moolgaoker, A. S., and Walsh, J. J. (1971). Lancet, 2 1245.

Strausz, I. K., and Schulman, H. (1971). Obstetrics and Gynecology, 38, 199.

\title{
Ultrasonic Fetal Cephalometry: Percentiles Curve
}

\author{
P. FLAMME
}

British Medical fournal, 1972, 3, 384-385

\section{Summary}

Measurements by ultrasound of the biparietal diameter of the fetal head during pregnancy are a reliable guide to fetal growth. As a ready means of comparison with the normal we constructed from 4,170 measurements in 1,394 cases a curve showing the percentiles distribution of biparietal diameters for each week of gestation.

\section{Introduction}

Ultrasonic fetal cephalometry has been practised for nearly 12 years (Donald and Brown, 1961). Willocks et al. (1964) showed that there was a correlation between birth weight and the ultrasonic measurement of the biparietal diameter before birth, and others have used the technique for measuring fetal

Free University of Brussels, Belgium

P. FLAMME, M.D., Assistant, Obstetric and Gynaecological Clinic

growth (Thompson et al., 1965). Also serial measurements of the growth rate of the biparietal diameter have shown it to be related to fetal maturity (Willocks et al., 1967).

The fetal biparietal diameter is measured as a guide to fetal development in most cases in the obstetric department of our hospital. At first a table giving the mean of biparietal diameters for each week of gestation was used as the standard of reference. We then thought it would be better to use a curve showing normal biparietal diameters expressed in terms of their percentiles distribution for each week of gestation. This paper describes how we constructed such a curve.

\section{Method and Results}

For the past five years we have used the A scan and B scan in combination in ultrasonic fetal cephalometry (Campbell, 1968). The measurements in millimetres of the biparietal diameters for each fetus are entered on a punched card with 32 spaces, the first for the serial number of the pregnancy and the remainder for measurements from the 14th to the 44th gestational weeks.

After eliminating all cases complicated by toxaemia, diabetes, or rhesus incompatibility and those in which placental insufficiency was suspected, measurements from 1,394 normal pregnancies were available for study. All the pregnancies ended 
Percentiles Distribution of Normal Fetal Biparietal Diameters in Millimetres for each Week of Gestation from 20th to 42nd

\begin{tabular}{|c|c|c|c|c|c|c|c|c|c|c|c|}
\hline \multirow{2}{*}{ Week } & \multicolumn{11}{|c|}{ Percentiles } \\
\hline & 10 & 20 & 25 & 30 & 40 & 50 & 60 & 70 & 75 & 80 & 90 \\
\hline $\begin{array}{l}20 \\
21 \\
22 \\
23 \\
24 \\
25 \\
26 \\
27 \\
28 \\
29 \\
30 \\
31 \\
32 \\
33 \\
34 \\
35 \\
36 \\
37 \\
38 \\
39 \\
40 \\
41 \\
42\end{array}$ & $\begin{array}{l}40 \\
42 \\
45 \\
48 \\
52 \\
54 \\
58 \\
60 \\
63 \\
66 \\
67 \\
72 \\
74 \\
76 \\
78 \\
80 \\
82 \\
84 \\
86 \\
87 \\
89 \\
90 \\
90\end{array}$ & $\begin{array}{l}40 \\
42 \\
46 \\
50 \\
54 \\
54 \\
60 \\
62 \\
66 \\
70 \\
70 \\
74 \\
76 \\
78 \\
80 \\
82 \\
84 \\
86 \\
88 \\
89 \\
90 \\
91 \\
91\end{array}$ & $\begin{array}{l}41 \\
45 \\
47 \\
50 \\
54 \\
56 \\
60 \\
63 \\
66 \\
70 \\
70 \\
74 \\
76 \\
78 \\
80 \\
83 \\
84 \\
86 \\
88 \\
90 \\
91 \\
92 \\
92\end{array}$ & $\begin{array}{l}42 \\
46 \\
48 \\
52 \\
55 \\
56 \\
62 \\
64 \\
66 \\
70 \\
71 \\
76 \\
78 \\
80 \\
82 \\
84 \\
85 \\
86 \\
88 \\
90 \\
91 \\
92 \\
92\end{array}$ & $\begin{array}{l}44 \\
48 \\
48 \\
54 \\
57 \\
58 \\
62 \\
66 \\
68 \\
72 \\
72 \\
76 \\
78 \\
80 \\
82 \\
84 \\
86 \\
88 \\
90 \\
90 \\
92 \\
93 \\
93\end{array}$ & $\begin{array}{l}44 \\
48 \\
50 \\
54 \\
58 \\
58 \\
64 \\
67 \\
70 \\
72 \\
74 \\
78 \\
80 \\
82 \\
84 \\
85 \\
86 \\
88 \\
90 \\
92 \\
92 \\
94 \\
94\end{array}$ & $\begin{array}{l}46 \\
50 \\
50 \\
54 \\
58 \\
60 \\
64 \\
68 \\
70 \\
72 \\
74 \\
80 \\
80 \\
82 \\
84 \\
86 \\
88 \\
89 \\
90 \\
92 \\
93 \\
94 \\
95\end{array}$ & $\begin{array}{l}46 \\
50 \\
52 \\
56 \\
60 \\
62 \\
65 \\
70 \\
72 \\
74 \\
76 \\
80 \\
82 \\
83 \\
86 \\
86 \\
88 \\
90 \\
92 \\
93 \\
94 \\
95 \\
96\end{array}$ & $\begin{array}{l}46 \\
51 \\
52 \\
56 \\
60 \\
62 \\
66 \\
70 \\
72 \\
74 \\
76 \\
80 \\
82 \\
84 \\
86 \\
88 \\
89 \\
90 \\
92 \\
94 \\
94 \\
96 \\
96\end{array}$ & $\begin{array}{l}46 \\
52 \\
53 \\
57 \\
60 \\
62 \\
66 \\
70 \\
72 \\
74 \\
76 \\
82 \\
84 \\
84 \\
86 \\
88 \\
90 \\
91 \\
92 \\
94 \\
95 \\
96 \\
97\end{array}$ & $\begin{array}{l}48 \\
54 \\
55 \\
59 \\
63 \\
66 \\
69 \\
74 \\
76 \\
76 \\
80 \\
84 \\
84 \\
86 \\
88 \\
90 \\
91 \\
92 \\
94 \\
95 \\
96 \\
97 \\
98\end{array}$ \\
\hline
\end{tabular}

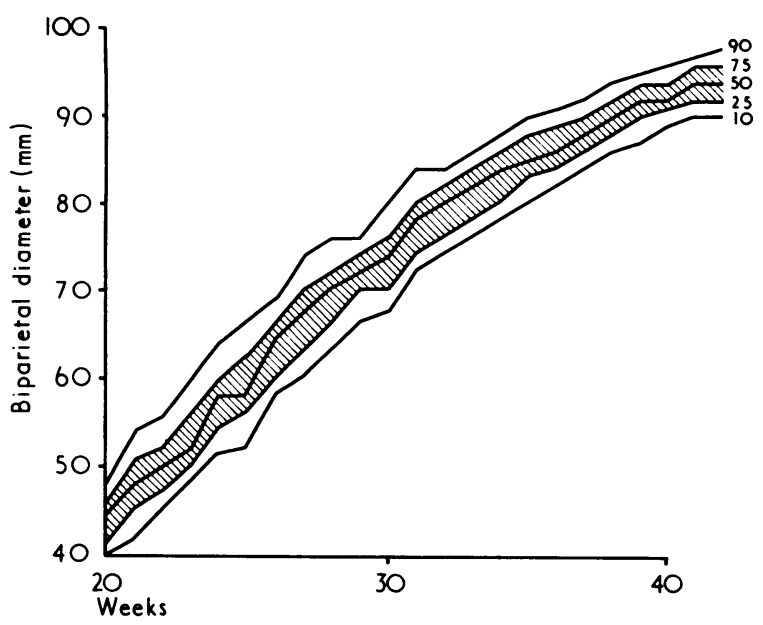

Curve showing percentiles distribution of normal biparietal diameters in Curve showing percentiles distribution of normal biparietal diameters in area indicates first and third quartiles (25th and 75 th percentiles).

at or after the 38th week and not later than the 42nd week. In each case the date of the last menstrual period was known and the gestational age was expressed in completed weeks from the first day of the last period. There were 4,170 measurements recorded on the 1,394 cards, which is an average of three measurements for each pregnancy.

The 1,394 cards were processed through the CDC 6400 computer of the Université Libre de Bruxelles. We noted the distribution of the measurements of the biparietal diameter among the weeks of gestation and the measurements corresponding to the various quantiles. The quantiles or fractiles of $\mathrm{k}$ order are the $\mathrm{k}-\mathrm{l}$ values which divide a statistical series into $\mathbf{k}$ classes of the same importance. The measurements were to the nearest millimetre, since our equipment cannot be more precise.

The 10th to 90th percentiles of the distribution for the 20th to the 42nd weeks, based on 3,961 measurements, were taken and the results are shown in the Table and in the curve constructed from it (see Chart). Measurements from the 14th to the 19th weeks were too few to be meaningful. We thought it would be helpful also to reproduce the first and third quartiles (25th and 75th percentiles), since the interquartile gap included half of the measurements which were located in the centre of the distribution.

\section{Comment}

By comparing the measurements of the biparietal diameter of the fetal head with the corresponding point on the curve it is possible to see in any pregnancy whether fetal growth is abnormal. Measurements which are regularly above the 90th or below the 10th percentile are not necessarily an indication of abnormality, but measurements which change upwards or downwards from one interdecile space to another should alert the observer to the possibility of hydrocephalus or placental insufficiency.

\section{References}

Campbell, S. (1968). Fournal of Obstetrics and Gynaecology of the British Commonwealth, 75, 568 .

Donald, I., and Brown, T. G. (1961). British Fournal of Radiology, 34, 539. Thompson, H. E., Holmes, J. H., Gottesfeld, K. R., and Taylor, E. S. (1965). American fournal of Obstetrics and Gynecology, 92, 44

Willocks, J., Donald, I., Duggan, T. C., and Day, N. (1964). Fournal of Obstetrics and Gynaecology of the British Commonwealth, 71, 11.

Willocks, J., Donald, I., Campbell, S., and Dunsmore, I. R. (1967). Fournal of Obstetrics and Gynaecology of the British Commonwealth, 74, 639. 